\title{
Ethnopharmacology, Pharmacology and Phytochemistry of Aristolochia bracteolata Lam: A Review of an Antimalarial Plant
}

\author{
Lina S. Mathew*a, b, Andrew G. Mtewa ${ }^{\text {b, c }}$, Clement O. Ajayi ${ }^{\mathrm{b}}$, Serawit Deyno ${ }^{\mathrm{b}, \mathrm{d}}$, Anke Weisheit ${ }^{\mathrm{b}}$, Casim \\ Umba Tolo ${ }^{\mathrm{b}}$, Arop L. Deng ${ }^{\mathrm{e}}$, Patrick Engeu Ogwang ${ }^{\mathrm{b}, \mathrm{f}}$ \\ aDepartment of Biology, College of Education, Bahr El Ghazal University, Wau, South Sudan

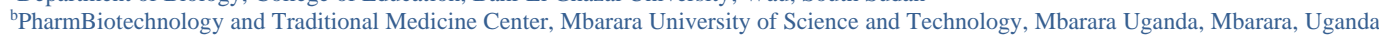 \\ ${ }^{\circ}$ Chemistry Section, Department of Applied Sciences, Malawi Institute of Technology, Malawi University of Science and Technology, Thyolo, Malawi \\ ${ }^{\mathrm{d} D e p a r t m e n t ~ o f ~ P h a r m a c o l o g y, ~ S c h o o l ~ o f ~ M e d i c i n e, ~ C o l l e g e ~ o f ~ M e d i c i n e ~ a n d ~ H e a l t h ~ S c i e n c e s, ~ H a w a s s a ~ U n i v e r s i t y, ~ H a w a s s a, ~ E t h i o p i a ~}$ \\ ${ }^{e}$ College of Natural Resources and Environmental Studies, Juba University, South Sudan \\ ${ }^{\mathrm{f}}$ Department of Pharmacy, Faculty of Medicine, Mbarara University of Science and Technology, Mbarara, Uganda, Mbarara Uganda. \\ *Corresponding to Lina S. Matthew (mathewlina@ymail.com or lmathew@std.must.ac.ug)
}

\begin{abstract}
Malaria remains one of the most common infectious diseases in the sub-Sahara African countries and other developing countries. Among the medicinal plants used in the endemic countries for the treatment of malaria is Aristolochia bracteolata Lam. due to its availability, accessibility, and traditional use. This study therefore reviewed the ethnomedicinal use, pharmacology, and the chemistry of Aristolochia bracteolata. Different electronic databases such as Medline/Pubmed, Cochrane Library, and Embase were searched to identify all published articles on Aristolochia bracteolata Lam. Key search words included ethnopharmacological use, pharmacological and phytochemical parameters of A. bracteolata. Retrieved articles were reviewed and synthesized. In addition, the reference list of retrieved articles was reviewed and articles which were not retrieved by previous search were hand searched. The review included original research articles that has investigated Aristolochia bracteolata Lam. of any study design. Only published original articles, any languages, any time of publish, and grey literature (Conference paper, theses both $\mathrm{PhD}$. and Msc. technical report) were included. Those articles with full text not available, those without information of interest, e.g ethnopharmacology, pharmacology and phytochemistry of A. bracteolata were excluded. Despite having multiple use, the plant is mainly used in the treatment of malaria with a reported antiplasmodial activity. Aristolochic acids (AAs) were reported as the major and active ingredient among other components in the plant. The review revealed that A. bracteolata has various traditional use with promising pharmacological activity. However, information on its safety is limited.
\end{abstract}

Keywords: Aristolochia bracteolata, Ethnopharmacology, Pharmacology, Phytochemistry, South Sudan, Malaria, Aristolochic acids.

\section{INTRODUCTION}

1 edicinal plants played a very important role in human comprise many chemical constituents with different pharmacological effects thereby regulating different biological mechanisms and treating different types of diseases ${ }^{1}$. They have a vital role in treating and preventing various diseases. Some of these medicinal plants have been reported for their antimalarial activities and have been the source of new lead drugs including artemisinin, quinine, etc. $^{2,3}$. In addition to antimalarial efficacy, some of these plants have been reported to exhibit antidiuretic, antiinflammatory, anti-analgesic, anticancer, antiviral, antibacterial and antifungal activities. The use of herbal medicine (HM) has become an alternative source of treatment over the past three decades to address the gap of 
high cost, resistance to conventional drugs and as alternative drug for primary healthcare $(\mathrm{PHC})^{4}$. Medicinal plants have played important roles in drug discovery through phytochemicals which can be directly used as medical remedy, structural basis for chemical synthesis or act as structural model for semi-synthetic drugs ${ }^{5}$. Medicinal plants are the richest bio-resource of drugs of traditional systems of medicine, modern medicines, nutraceuticals, food supplements, folk medicines, antimalarial drugs etc ${ }^{4}$. Many plants are useful to human lives as source of food, food supplement or therapeutic purpose, however, some have been reported to have mutagenic and genotoxic effect in vivo ${ }^{6}$. Plant toxicity may arise from contaminants like lead, mercury, arsenic and other that can be absorbed from the soils or from the end products of plant metabolism. Current studies have focused more on ethnomedicinal use, pharmacology and phytochemistry of medicinal plants used by humans. This is very significant in order to guarantee the safety of the consumers of plant products ${ }^{7}$. The plant toxicity may originate from different contaminants which may be chemical (organic pollutant, toxic metals or non-metals), biological (parasitic or microbiological) or agrochemical residues $^{8}$. A number of bioassays are used in research to ascertain toxicity level of medicinal plants or herbal extracts which may be in vivo using laboratory animals ${ }^{9}$ or in vitro using cell line cytotoxicity studies ${ }^{10}$. Identification of phytochemicals responsible either for biological activity or toxicity is important for enhancing the bioactive effect or preventing the toxic effect. In malaria endemic countries, medicinal plants are used as alternative for treatment of the different ailments including malaria, and has remained a first line source of novel drugs such as quinine, artemisinins etc. Aristolochia bracteolata is used for the treatment of various diseases in many countries including South Sudan but review on its safety, phytochemistry and efficacy is limited. This review synthesized information on ethnopharmacology, pharmacology and phytochemistry of Aristolochia bracteolata Lam.
Different electronic databases searches were performed in Medline/Pubmed, Cochrane Library, Google scholar, proquest library and Embase to identify all published articles on Aristolochia bracteolata Lam. The key words included ethnopharmacological use, pharmacological and phytochemical parameters of Aristolochia bracteolata. In addition, the reference list of retrieved articles was reviewed and articles which were not retrieved by previous search were hand searched. The review included original research articles that has investigated Aristolochia bracteolata Lam. of any study design. Only published original articles, any languages, any time of publish, and grey literature (Conference paper, theses both $\mathrm{PhD}$. and MSc., technical report) were included. Full text not available, those without information of interest, e.g. ethnopharmacology, pharmacology and phytochemistry of A. bracteolata were excluded.

\section{RESULTS}

Search results

After searching the data bases and hand searching a total of 215 articles were obtained. After reviewing articles for relevance, 73 were excluded. Since 23 full text were not available, 5 were reviewed articles, and the remaining does not have the information of interest. Therefore, 42 articles were finally included in this review.

Botany of Aristolochia bracteolata Lam.

The Plant A. bracteolata Lam. belongs to the family Aristolociaceae. The genus aristolochia has over 500 species, but those reported to be found in Africa includes; $A$. elegans, A. chilensis, A. clematitis A. albida, A. baetica. A. embergeri, A. heppi, A. hockii, A. fontanesii, A. paucinervis, A. pistolochia, A. rigida, A. sempervirens and $A$. bracteolata $^{11}$. Aristololochia bracteolata is a climbing perennial plant with cordate leaves and dark-purple colour tubular flowers widely distributed in tropical Asia, Africa and South America ${ }^{12}$. It is commonly known as worm killer and classification details are provided in Table 1.

\section{METHODS}

TABLE 1. Classification of Aristolochia bracteolata Lam.

\begin{tabular}{ll}
\hline Family & Aristolochiaceae \\
\hline Genus & Aristolochia \\
Species & A. bracteolata \\
Scientific name & Aristolochia bracteolata Lam. \\
Synonyms & Aristolochia bracteata Retz., Aristolochia benadirana Flori., Aristolochia abbyssinica Klotzch., \\
& Aristolochia mauritiana Pers. Aristolochia crenata Ehreb ex.Duch. \\
Common names & Wormkiller, Dikeritimelo. Morodi. \\
Habit & Climbing herb \\
Habitat & Dry areas, black cotton soil, riverbanks, bush lands, desert grassland and sandy soil. \\
Propagation & Seed \\
\hline
\end{tabular}


Ethnopharmacology of Aristolochia bracteolata Lam. Aristolochia bracteolata Lam. was the leading antimalarial plant reported in the list of medicinal plants in South Sudan $^{13}$. Other various plants that are used for the treatment of malaria include Gardenia thunbergia, Cucumis dipsaceus, Tamarindus indica, Balanites aegyptiaca, and cassia nigricans ${ }^{13}$. Apart from treating malaria, A. bracteolata is also used for treatment of various diseases and ailments in South Sudan traditional health system. These uses include dysentery, headache, fever, general body pain, snake bites, scorpion bites, high blood pressure, diabetes, diarrhea and stomach ache ${ }^{13}$. The whole plant has been reported to be of medicinal importance ${ }^{13}$. The plant $A$. bracteolata Lam. is the most commonly used as an antimalarial plant and sold in the markets as a source of income for the local inhabitants in South Sudan. The whole plant is either administered fresh or after sun dried. For the topical use, the plant paste is applied in the affected area and seeds are swallowed for the treatment of malaria and other stomach conditions. Its root is also powdered, infused in water and administered orally for the treatment of malaria, fever, headache, general body pain, stomachache, diarrhea and flu $^{13}$. Table 2 depicts ethnopharmacological uses of different parts of $A$. bracteolata.

TABLE 2. Ethnopharmacological uses of different parts of Aristolochia bracteolata Lam.

\begin{tabular}{llc}
\hline Plant part & Used & Reference \\
\hline Whole Plant & $\begin{array}{l}\text { Is crushed, soaked in water taken orally as gastric stimulant treatment, cancer, } \\
\text { lungs inflammation dysentery, and snake bite }\end{array}$ & 14 \\
Whole Plant & $\begin{array}{l}\text { For treatment of Malaria, convulsions, abdominal pain, scorpion stings, flu, } \\
\text { vomiting, pneumonia, polymeorrhea and edema }\end{array}$ & 15 \\
Root & $\begin{array}{l}\text { Root paste as vulnerary agent: 100g of fresh roots taken processed and ground to } \\
\text { paste. It is mixed with 1 spoonful of turmeric powder, warmed and applied on }\end{array}$ & 16 \\
& wounds \\
Root and Leaf & Roots used for Scorpion stings and anti-inflammatory, leaves for malaria \\
The Whole Plant & For the treatment of malaria and other conditions like, fever, headache, general \\
& body pain, stomachache, diarrhea and flu. & 17 \\
\end{tabular}

Pharmacological activity of Aristolochia bracteolata Lam. Aristolochia bracteolaae Lam. has been reported to have antibacterial, antifungal ${ }^{18}$, anti-arthritis ${ }^{19}$, hypotensive, hypothermia, antioxidant, anti-inflammatory, antihyperglycemic and antihyperlipidemic ${ }^{20}$ activities. Hexane extract of A. bracteolata showed in vitro antiplasmodial activity on chloroquine sensitive $P$. falciparum MRC-2 strain with $\mathrm{IC}_{50}$ of $16 \mu \mathrm{g} / \mathrm{mL} .^{21}$. In another study, methanol extract of seed and root of $A$. bracteolata showed in vitro antiplasmodial activity on chloroquine resistant and pyrimethamine sensitive strain with $\mathrm{IC}_{50}$ less than $5 \mu \mathrm{g} / \mathrm{mL}$. Likewise, petroleum ether/chloroform extract of whole plant of $A$. bracteolata showed in vitro antiplasmodial activity of $100 \%$ inhibition against $P$. falciparum at $50 \mu \mathrm{g} / \mathrm{mL}$ concentration ${ }^{17,22}$. This confirms local community claim that the plant has effect on malaria parasite. Antimicrobial activity ${ }^{23}$ anti-arthritis activity $^{24}$, anti-allergic activity ${ }^{19}$ and anti-oxidant property ${ }^{25}$ were also exhibited by the plant. The ethyl acetate, acetone and methanol extracts of the root showed promising antibacterial activity on Gram positive and Gram negative bacteria, with ethyl acetate extract being the most effective $^{14}$. Aristolochia bracteolata showed a promising hyperuricemia in a metabolic arthritis rat model ${ }^{1}$ and showed a potent in vitro wound healing action through anti- inflammatory and proliferative effect on human dermal fibroblasts and keratinocytes ${ }^{26}$.

Phytochemistry of Aristolochia bracteolata Lam.

Phytochemical screening of Aristolochia bracteolata Lam. showed that it contains presence of alkaloids, saponins, flavonoid, phenol and tannin ${ }^{16}$. Methanol extract of $A$. bracteolata subjected

to phytochemical screening has shown the presence of phenolic compounds, flavonoids, triterpenoids, alkaloids, steroids, cardiac glycosides, saponins and aristolochic acids A-D ${ }^{4}$. The stem and the root were reported to contain the alkaloid and aristolochic acids. The chief active principle of the drug is aristolochic acid, though aristolic and p-coumaric acids also appear to contribute to the activities of the drug. Aristolochic acid is 8-methoxy-3; 4-methylenedioxy - 10 nitrophenanthrene - 1-carboxylic acid. It is intensely bitter and is optically inactive. It is the same as iso-aristolochic acid, aristolochia yellow, aristinic and aristolochic acids, but is different from aristolochine now identified as 1-curine. The aristolochic acids were host of phenanthrene derived metabolites in which the aristolactams also possessed the similar skeleton ${ }^{27}$. Both aristolochic acids (AAs) I and II are the major components of the plant in aristolochia genus. Phytochemical screening 
of A. bracteolata using different solvents is presented in Figures 1 and $\mathbf{2}$ and Table 3 depict structures of aristolochic acid I and II respectively. However, in another study, methanolic extract of A. bracteolata Lam was purified and toxic compounds identified as AAs were isolated using different purification techniques. It was noted in previous studies that the whole plant $(200 \mathrm{~g})$ was defatted to produce dark green oily residue $(5.35 \%)$. High performance liquid chromatography (HPLC) data also showed that AA-II was represented in a higher calculated quantity of $49.03 \mathrm{~g} / \mathrm{kg}$ compared to AA-I $(12.98 \mathrm{~g} / \mathrm{kg})$ in A. bracteolata L. whole plant $^{31,32}$. Although evidence of the presence of aristolochic I and II in A. bracteolata Lam. is reported by Achenbach and Fischer $^{33}$, Kumar ${ }^{34,35}$ reported absence of Aristolochic II in this plant. Variation in their results may be explained by the different techniques and methods of analysis used.

FIGURE 1: $\mathrm{C}_{17} \mathrm{H}_{11} \mathrm{NO}_{7}$; Relative molecular mass: 341.27

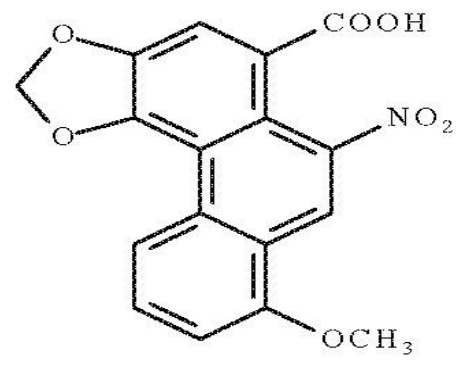

FIGURE 2. $\mathrm{C}_{16} \mathrm{H}_{9 \mathrm{NO}}$; ; Relative molecular mass: 311.25 
TABLE 3. Phytochemical screening of Aristolochia bracteolata Lam. using different solvents

\begin{tabular}{|c|c|c|c|}
\hline Plant Part Used & Extract Solvents & Phytochemicals & Reference \\
\hline Whole Plant & Methanol Extract & $\begin{array}{l}\text { Presence of alkaloids, triterpenoids, glycosides, steroids, } \\
\text { tannins, phenolic compounds, flavonoids and cardio } \\
\text { glycosides }\end{array}$ & 27 \\
\hline Whole Plant & Methanol & $\begin{array}{l}\text { phenolic compounds, flavonoids, triterpenoids, alkaloids, } \\
\text { steroids, cardiac glycosides, saponins and aristolochi acid-A, } \\
\text { and aristolochic acid-D }\end{array}$ & 24 \\
\hline Leaf Part & $\begin{array}{l}\text { Methanol \& ethyl } \\
\text { acetate }\end{array}$ & $\begin{array}{l}\text { Presence of alkaloids, glycosides, phytosterol, saponins, } \\
\text { tannins, phenol, carbohydrates }\end{array}$ & 28 \\
\hline Leaf & $\begin{array}{l}\text { Increasing order of } \\
\text { polarity from } \\
\text { petroleum ether to } \\
\text { benzene, chloroform, } \\
\text { acetone and alcohol } \\
\text { extract }\end{array}$ & $\begin{array}{l}\text { Presence of alkaloids, saponin, glycosides, steroids, tannins, } \\
\text { phenolic compounds, flavonoids }\end{array}$ & 29 \\
\hline Leaf & Methanol extract & $\begin{array}{l}\text { Presence of alkaloids, saponin, steroids, tannins, terpenoids, } \\
\text { flavonoids and glycosides }\end{array}$ & 30 \\
\hline Leaf & Aqueous extract & $\begin{array}{l}\text { Presence of alkaloids, saponins, steroids, tannins, phenol } \\
\text { flavonoids, carbohydrates and glycosides }\end{array}$ & 28 \\
\hline
\end{tabular}

Toxicity of Aristolochia bracteolata Lam.

Most of the plant family Aristolochiaceae are said to contain aristolochic acids (AAs) ${ }^{15}$. Pure AAs from A. bracteolata plant has been reported for nephrotoxic, mutagenic and carcinogenic in the tested animals after a prolong administration. In experimental animals, high doses of aristolochic acids administered either orally or intravenously caused severe necrosis of the renal tubules ${ }^{36}$. However, there is limited evidence in human on the carcinogenicity of the plant. The acute oral toxicity study on A. bracteolata extract showed no mortality and any sign of toxicity after dosing at $2000 \mathrm{mg} / \mathrm{kg}^{7}$. In a similar study, ${ }^{29,32}$ the ethanol extract of $A$. bracteolata administered orally at 1000, 2000, 3000, 4000, and $8000 \mathrm{mg} / \mathrm{kg}$ did not produce any sign of toxicity and mortality in rats when observed for 14 days postadministration, which could be safety-acutely.

The kidney is an important organ required by the body to perform several important functions including the maintenance of homeostasis, power of hydrogen $(\mathrm{PH})$, blood pressure (BP), regulation of the extracellular environment, such as detoxification, and excretion of toxic metabolite and drugs. Kidney is also a major site of organ damage caused by drug toxicity ${ }^{37}$. Nephron is a basic unit structure in the kidney which functions to remove waste products, stray ions and excess water from the blood. Therefore, the kidney can be considered as a major target organ for exogenous toxicants due to nephrotoxicity ${ }^{38-40}$.
Aristolochic acid administered orally on rats at $50 \mathrm{mg} / \mathrm{kg}$ for three days neoplastic lession on the kidneys were reported ${ }^{41}$. In another study, aristolochic acids administered through intraperitoneal injection on rabbits at $0.1 \mathrm{mg} / \mathrm{kg}$ for $17-21$ months reported kidney tumors, ulcers, and peritoneal cavity $^{34}$.

However, it is important to recognize that safety concerns must be incorporated into a general 'risk-benefit' analysis and that toxicity of a drug does not necessarily mean that it should not be developed or approved. The aminoglycoside antibiotics, the cancer drug cisplatin and the antiviral tenofovir were some of the few mentioned examples of drugs which are proved to be nephrotoxic but efficacious in terms of treatment ${ }^{42}$.

\section{CONCLUSION}

This review study has shown that Aristolochia bracteolata Lam. is used as remedy for different ailment and unlike pure aristolochic acids which is toxic, the extracts did not show any sign of toxicity from the literature. The plants have also shown a promising antiplasmodial activity which could be recommended for antimalarial study in vivo. It could be concluded that the plant contains different chemical constituents with aristolochic acids being the marker which is reported for a degenerative effect on the organs. This plant however has shown a promising pharmacology which could be explored in the development of future drugs development. 
Acknowledgements: The authors would like to acknowledge PharmBiotechnology and Traditional Medicine Centre (PHARMBIOTRAC) project for making this work possible.

\section{REFERENCES}

1. Li YP, Wu S, Ran A, Xu DY, Wei JM, Zhao ZL. Aristolochia Bracteolate Retz. Attenuates Hyperuricemia in a Metabolic Arthritis Rat Model. Afr J Tradit Complement Altern Med. 2017;14(4):180-187. doi:10.21010/ajtcam.v14i4.21

2. Kong LY, Tan RX. Artemisinin, a miracle of traditional Chinese medicine. Nat Prod Rep. 2015;32(12):1617-1621.

3. Achan J, Talisuna AO, Erhart A, et al. Quinine, an old anti-malaria drug in a modern world: Role in the treatment of malaria. Malar J. 2011;10:1-12. doi:10.1186/1475-2875-10-144

4. Tiwari P, Kumar B, Kaur M, Kaur G, Kaur H. Phytochemical Screening and Extraction: A Review. Vol 1.; 2011.

5. Feng TS, Guantai EM, Nell M, et al. Effects of highly active novel artemisinin-chloroquinoline hybrid compounds on $\beta$-hematin formation, parasite morphology and endocytosis in Plasmodium falciparum. Biochem Pharmacol. 2011;82(3):236-247. doi:10.1016/j.bcp.2011.04.018

6. askin celik T, Aslantürk Ö. Cytotoxic and Genotoxic Effects of Lavandula Stoechas Aqueous Extracts. Vol 62.; 2007. doi:10.2478/s11756-007-0051-2

7. Raju MG, Reddy THS. Antii Diabetic and Hypolipidemic activity of methanolic extrat of Aristolochia bracteolata on streptozotocin induced diabetic Rat model. IJPSR. 2017;8(3):1174-1177.

8. WHO. WHO Guidelines for Assessing Quality of Herbal Medicines with Reference to Contaminants and Residues. World Health Organization; 2007.

9. Ekor M. The growing use of herbal medicines: issues relating to adverse reactions and challenges in monitoring safety. Front Pharmacol. 2014;4(177):10.

10. Ifeoma O, Oluwakanyinsola S. Screening of Herbal Medicines for Potential Toxicities. Intech ; 2013.

11. De Groot H, Wanke S, Neinhuis C. Revision of the genus Aristolochia (Aristolochiaceae) in Africa, Madagascar and adjacent islands. Bot $J$ Linn Soc. 2006;151(2):219-238. doi:10.1111/j.1095-8339.2006.00511.x

12. Samia HAR, Elmalik KH, Khalid HS. Therapeutic Effect of Aristolochia bractealata Extract Against Experimental Trypanosoma evansi Infection. Int J Trop Med. 2006;1(4):170-172.

13. Mathew LS. Ethnobotanical Survey on Wild Edible and Medicinal Plants in Torit County, Eastern Equatoria State, South Sudan. Thesis Submitt to Biol Dep Sch Educ Univ Libr Sch Post Grad Univ Juba. 2016.

14. Negi PS, Anandharamakrishnan C, Jayaprakasha GK. Antibacterial activity of Aristolochia bracteata root extracts. J Med Food. 2003;6(4):401-403.

15. Heinrich M, Chan J, Wanke S, Neinhuis C, Simmonds MSJ. Local uses of Aristolochia species and content of nephrotoxic aristolochic acid 1 and 2-A global assessment based on bibliographic sources. $J$ Ethnopharmacol. 2009;125(1):108-144. doi:10.1016/j.jep.2009.05.028

16. Bharath Kumar R, Suryanarayana B. Ethnomedicinal recipes for digestive ailments and stomachic problems \& allied diseases from tribals of Sriharikota island, Andhra Pradesh. Int J Pharma Bio Sci. 2014;5(1):B468-B482

https://www.scopus.com/inward/record.uri?eid=2-s2.0$84892447700 \&$ partnerID $=40 \& \mathrm{md} 5=6 \mathrm{a} 47136 \mathrm{~b} 299 \mathrm{ca} 1333906 \mathrm{f} 5 \mathrm{af} 7 \mathrm{c} 2 \mathrm{c} 9$ d36.

17. Ahmed EHM, Nour BYM, Mohammed YG, Khalid H s. Antiplasmodial Activity of Some Medicinal Plants Used in Sudanese Folk-medicine. Environ Health Insights. 2010;4(February). doi:10.4137/EHI.S4108

18. Kavitha D, Nirmaladevi R. Assessment of Aristolochia Bracteolata Leaf Extracts for Its Biotherapeutic Potential. Vol 8.; 2010.

19. Chitme HR, Malipatil M, Chandrashekhar VM, Prashant PM. Antiallergic activity of Aristolochia bracteolata Lank in animal model.
Indian J Exp Biol. 2010;48(1):46-52.

20. FDA. Guidance for Industry, Clinical development programs for drugs, devices, and biological products for the treatment of rheumatoid arthritis. 1999; http://www.

21. Rana D, Mehta DS, Desai KR, Highland HN, George LB. Effects of the extracts of Aristolochia and Tylophora species on Plasmdoium falciparum in vitro. Int J Pharm Res. 2012;4(4):79-81. doi:10.13140/2.1.5015.3607

22. Tahir A El, Satti GMH, Khalid SA. Antiplasmodial activity of selected Sudanese medicinal plants with emphasis on Maytenus senegalensis (Lam.) Exell. J Ethnopharmacol. 1999;64(3):227-233. doi:10.1016/S0378-8741(98)00129-9

23. Manikandar R V, Selvamani P, Latha S. Antibacterial Activity of Leaf Extracts of Aristolochia Bracteate Retz. Vol 68.; 2006. doi:10.4103/0250-474x.27830

24. Khandelwal KR. Practical Pharmacognosy Techniques and Experiments. Pune: Nirali Prakashan; 2005.

25. Devi K, Kanimozhi S, Suganyadevi P. Phytochemical screening and biological property of Aristolochia bracteolata. J Pharm Res. 2011;4(5):1509 - 1514.

26. Girija DM, Kalachaveedu M, Subbarayan R, Jenifer P, Rao SR. Aristolochia bracteolata enhances wound healing in vitro through antiinflammatory and proliferative effect on human dermal fibroblasts and keratinocytes. Pharmacogn J. 2017;9(6):s129-s136. doi:10.5530/pj.2017.6s.169

27. Nandhini DU, Rajasekar M, Venmathi T, Koopen AW. A review on worm killer: Aristolochia bracteolata. J Pharmacogn Phytochem. 2017;6(2):6-9.

28. Palanisamy K, Deepa M, Pushpa R, andM Lenin PK. Screening and characterization of Aristolochia bracteolata plant extract against antibacterial activity of selected microbes. J Pharmacogn Phytochem. 2019;8(3):4573-4576.

29. Shirwaikar A, Somashekar AP, Udupa AL, Udupa SL, Somashekar S. Wound healing studies of Aristolochia bracteolata Lam. with supportive action of antioxidant enzymes. Phytomedicine. 2003;10(67):558-562. doi:10.1078/094471103322331548

30. Lavanya A, Ambikapathy V, Panneerselvam A. In vitro Callogenesis and Phytochemical analysis of Aristolochia bracteolata Lam - A Multipotent Medicinal Plant. Int J Recent Sci Res. 2016;7:1288712890.

31. Abdelgadir AA, Boudesocque-Delaye L, Thery-Koné I, Gueiffier A, Ahmed EM, Enguehard-Gueiffier C. One-step preparative isolation of aristolochic acids by strong ion-exchange centrifugal partition chromatography. Sep Purif Technol. 2015;156:444-449. doi:https://doi.org/10.1016/j.seppur.2015.10.033

32. Abdelgadir AA, Ahmed EM, Eltohami MS. Isolation, Characterization and Quantity Determination of Aristolochic Acids, Toxic Compounds in Aristolochia bracteolata L. Env Heal Insights. 2011;5:1-8.

33. Achenbach H, Fischer A. 6-O-beta-d-Glucoside of aristolochic acid IIIa and other components from the roots of Aristolochia baetica. . Planta Med. 1997;63:579.

34. Cosyns JP. Aristolochic acid and 'Chinese herbs nephropathy': a review of the evidence to date. Drug Saf. 2003;26:33-48.

35. Kumar V, Poonam, Prasad AK, Parmar VS. Naturally occurring aristolactams, aristolochic acids and dioxoaporphines and their biological activities. Nat Prod Rep. 2003;20(6):565-583.

36. Chen SM, Fan MY, Tseng CC, Ho Y, Hsu KY. Pharmacokinetics and nephrotoxicity of aristolochic acid in rabbits. Toxicon. 2007;50(2):180188. doi:10.1016/j.toxicon.2007.03.011

37. Ferguson MA, S. V V. Biomarkers of nephrotoxic acute kidney injury. Toxicology. 2008;245:182-193.

38. Kohli HS, Bhaskaran MC, Muthukumar T, et al. Treatment-related acute renal failure in the elderly: a hospital-based prospective study. Nephrol Dial Transplant. 2000;15:212-217.

39. Nagai J, Takano M. Molecular-targeted approaches to reduce renal accumulation of nephrotoxic drugs. Expert Opin Drug Metab Toxicol. 2010;6:1125-1138.

40. Naughton CA. Drug-induced nephrotoxicity. Am Fam Physician. 2008;78:743-750 
41. Cui M, Liu ZH, Qiu Q, Li H, Li LS. Tumour induction in rats following exposure to short-term high dose aristolochic acid I. Mutagenesis. 2005;20(1):45-49. doi:10.1093/mutage/gei007

42. Bonventre J V, Vaidya VS, Schmouder R, Feig P, Dieterle F. Nextgeneration biomarkers for detecting kidney toxicity . Nat Biotechnol. 2010;28(5):436-440. doi:10.1038/nbt0510-436
Peer Reviewed

Competing Interests: None declared.

Received: 29 Dec 2019; Accepted: 23 Apr 2020

Cite this article as: Mathew LS, Mtewa AG, Ajayi C, Deyno S, Weisheit A, Tolo CU, Deng AL, Ogwang PE. Ethnopharmacology, Pharmacology and Phytochemistry of Aristolochia Bracteolata Lam: A Review of An Antimalarial Plant. E Afr Sci. 2020;1(2):22-28. http://doi.org/10.24248/EASci-D-19-00011

(C) Mathew et al. This is an open-access article distributed under the terms of the Creative Commons Attribution License, which permits unrestricted use, distribution, and reproduction in any medium, provided the original author and source are properly cited. To view a copy of the license, visit http://creativecommons.org/licens- es/by/4.0/. When linking to this article, please use the following permanent link: http://doi.org/10.24248/EASci-D-19-00011 